\title{
Do drowning and anoxia kill head lice?
}

\author{
Kerdalidec Candy ${ }^{1,3}{ }^{*}$, Sophie Brun ${ }^{1}$, Patrick Nicolas ${ }^{2}$, Rémy Durand ${ }^{1}$, Remi N. Charrel ${ }^{3}$, and Arezki Izri ${ }^{1,3}$ \\ ${ }^{1}$ Parasitology-Mycology Department, Avicenne Hospital, AP-HP, Bobigny, France \\ ${ }^{2}$ Unit of Pharmacology, Avicenne Hospital, AP-HP, Bobigny, France \\ ${ }^{3}$ Unité des Virus Emergents (Aix-Marseille Univ - IRD 190 - Inserm 1207 - IHU Méditerranée infection), Marseille, France
}

Received 31 August 2017, Accepted 25 February 2018, Published online 9 March 2018

\begin{abstract}
Chemical, physical, and mechanical methods are used to control human lice. Attempts have been made to eradicate head lice Pediculus humanus capitis by hot air, soaking in various fluids or asphyxiation using occlusive treatments. In this study, we assessed the maximum time that head lice can survive anoxia (oxygen deprivation) and their ability to survive prolonged water immersion. We also observed the ingress of fluids across louse tracheae and spiracle characteristics contrasting with those described in the literature. We showed that $100 \%$ of lice can withstand $8 \mathrm{~h}$ of anoxia and $12.2 \%$ survived $14 \mathrm{~h}$ of anoxia; survival was $48.9 \%$ in the untreated control group at $14 \mathrm{~h}$. However, all lice had died following $16 \mathrm{~h}$ of anoxia. In contrast, the survival rate of water-immersed lice was significantly higher when compared with non-immersed lice after $6 \mathrm{~h}(100 \%$ vs. $76.6 \%, p=0.0037)$, and $24 \mathrm{~h}(50.9 \%$ vs. $15.9 \%, p=0.0003)$. Although water-immersed lice did not close their spiracles, water did not penetrate into the respiratory system. In contrast, immersion in colored dimeticone/ cyclomethicone or colored ethanol resulted in penetration through the spiracles and spreading to the entire respiratory system within $30 \mathrm{~min}$, leading to death in $100 \%$ of the lice.
\end{abstract}

Keywords: Pediculus humanus capitis, drowning, water, anoxia, oxygen

\begin{abstract}
Résumé - La noyade et l'anoxie tuent-elles les poux de tête? Des méthodes chimiques, physiques et mécaniques sont utilisées pour contrôler les poux humains. Des tentatives ont été faites pour éradiquer les poux de tête Pediculus humanus capitis par l'air chaud, en les trempant dans divers fluides ou en les asphyxiant à l'aide de traitements occlusifs. Dans cette étude, nous avons évalué le temps maximum que les poux de tête peuvent survivre à l'anoxie (privation d'oxygène) et leur capacité à survivre à une immersion prolongée dans l'eau. Nous avons également observé la pénétration de fluides à travers les trachées des poux et les caractéristiques du spiracle, contrastant avec celles décrites dans la littérature. Nous avons montré que $100 \%$ des poux supportent $8 \mathrm{~h}$ d'anoxie et que $12,2 \%$ survivent à $14 \mathrm{~h}$ d'anoxie; $48,9 \%$ de survie à $14 \mathrm{~h}$ a été obtenu dans le groupe témoin non traité. Cependant, tous les poux sont morts après $16 \mathrm{~h}$ d'anoxie. En revanche, le taux de survie des poux immergés était significativement plus élevé que celui des poux non immergés après $6 \mathrm{~h}(100 \%$ contre $76,6 \%, \mathrm{p}=0,0037)$ et $24 \mathrm{~h}$ $(50,9 \%$ contre $15,9 \%, \mathrm{p}=0,0003)$. Bien que les poux immergés dans l'eau n'aient pas fermé leurs spiracles, l'eau n'a pas pénétré dans le système respiratoire. En revanche, l'immersion dans de la diméticone/cyclométhicone colorée ou de l'éthanol coloré a entraîné une pénétration à travers les spiracles et une propagation à l'ensemble du système respiratoire dans les 30 minutes, entraînant la mort de 100 \% des poux.
\end{abstract}

\section{Introduction}

Lice are obligate human hematophagous ectoparasites belonging to the Pediculidae family [14,54]. Pediculosis infestation due to head lice (Pediculus humanus capitis De Geer, 1778) has a global distribution and affects individuals of broad economic or social status worldwide, particularly school-aged children $[19,25]$. Several studies have reported

\footnotetext{
${ }^{*}$ Corresponding author: Laboratoire de Parasitologie-Mycologie, Hôpital Avicenne, 125 rue de Stalingrad, 93009 Bobigny Cedex, France. candykerdalidec@yahoo.fr
}

the presence of Acinetobacter spp., Bartonella quintana, and Borrelia recurrentis in head lice [2,5-6]. Furthermore, laboratory experiments have demonstrated the ability of head lice to transmit pathogens such as Rickettsia prowazekii $[23,41,49]$ but whether or not there is a medical impact is still debated. Pediculosis capitis is also a source of social concern worldwide. Head lice may induce skin irritation, superinfection from scratching, social stigmatization, and psychological distress $[17,24,39]$. The economic implications are also substantial [26,27,40].

Different chemical, physical, and mechanical methods are used to control pediculosis. Use of insecticides such as 
pyrethrin or malathion was the treatment of choice until recently $[7,16]$. However, alternative treatments $[8,9,28]$ are currently replacing insecticide use due to widespread resistance to neurotoxic agents [18]. Since the early 2000s, different physical acting treatments based on various oils, alcohol or plant extracts have been tested in vitro or in clinical trials $[1,7,10,21,34,35,43,44,48,57]$. Some products appear to asphyxiate nits and lice by blocking air uptake at the surface $[35,44]$, whereas others achieve this by penetrating the tracheal system $[1,48]$. However, whether or not death was caused by asphyxiation remains under debate [10,11].

The efficacy of lice infestation treatment has been compared using a variety of protocols, including: hot and cold air [13,22], machine laundering [30,36,51], immersion in water [4,38,52], immersion in chemical agents [3], and immersion in ethanol $[37,50]$. The efficacy of chemical agents and ethanol has been demonstrated [3,37,50], whereas the efficacy of water remains controversial. Moreover, controversy exists concerning the role of spiracles during immersion.

Accordingly, we conducted the following experiments to investigate: (i) how long head lice can survive under anoxic conditions, (ii) the ability of head lice to survive up to $24 \mathrm{~h}$ when immersed in water, (iii) the closure of their spiracles when immersed in water, and (iv) the penetration of water and other products into the respiratory system of head lice.

\section{Materials and Methods \\ Ethics}

The protocol was reviewed and approved by the Comité de Protection des Personnes (institutional review board) of the Ethics Committee CPP- Ile-de-France X (2017-02). Informed consent was obtained from all patients.

\section{Collected lice}

From September 2015 to July 2016, Pediculus humanus capitis were obtained by combing the hair of infested patients of 2-68years of age attending the parasitology department of the Avicenne Hospital, Bobigny, France. Head lice were placed in plastic Petri dishes and were examined for activity and morphological integrity under a binocular magnifier (Zeiss Stemi 2000C). Tests were performed using living, non-injured lice. We started experiments immediately after lice collection. All experiments were done under the same conditions of diet, temperature of water $\left(25 \pm 2{ }^{\circ} \mathrm{C}\right)$, and ambient air $\left(25 \pm 2{ }^{\circ} \mathrm{C}, 20-50 \%\right.$ relative humidity).

\section{Anoxia bioassay}

To evaluate the effect of anoxia on head lice survival, ten groups of 30 lice each were used. Each group $(n=30)$ was placed in a plastic Petri dish (5 $\mathrm{cm}$ in diameter) and was placed in an AnaeroGen ${ }^{\mathrm{TM}}$ Compact plastic pouch (Oxoid Ltd, Basingstoke, England, UK). Then, the
AnaeroGen ${ }^{\mathrm{TM}}$ Compact sachet (Oxoid Ltd, Basingstoke, England, UK) was quickly placed in the pouch. The system was tied shut with a clip. Each group endured anoxia for one time point (H1, H3, H6, H8, H10, H12, H14, H16, H18, and H24). Each test group had a control group $(n=30)$ that was placed in a plastic Petri dish under ambient conditions $\left(25 \pm 2{ }^{\circ} \mathrm{C}, 20-50 \%\right.$ relative humidity). The pouches were then opened and viable and dead lice were counted separately $(\leq 1 \mathrm{~h})$ for the test and control groups, respectively. Death was defined as the absence of vital signs such as movement of antennae, movements of legs, and gut peristalsis. Each experiment was performed in triplicate.

\section{Lice survival after water immersion}

Seven groups of lice $(n=7-18$ each) were placed in plastic Petri dishes $(5 \mathrm{~cm}$ in diameter) and kept immersed in $10 \mathrm{~mL}$ of tap water $\left(24^{\circ} \mathrm{C}\right)$ for $\mathrm{H} 1$ to $\mathrm{H} 6$, and $\mathrm{H} 24$. Petri dishes were gently agitated until all lice were completely submerged and resting at the bottom, and then covered with their lid to prevent water evaporation. After the immersion period, water was removed and live or dead lice were counted. Seven groups of control lice $(n=7-18$ each) were placed in Petri dishes without water under room conditions $\left(25 \pm 2{ }^{\circ} \mathrm{C}, 20-50 \%\right.$ relative humidity) for the corresponding duration ( $\mathrm{H} 1$ to $\mathrm{H} 6$, and $\mathrm{H} 24$ ) and were processed similarly. The 7 to 18 lice used in each group were of both sexes. The experiments were performed in triplicate. Death was defined as described above.

\section{Effect of water immersion on lice spiracles}

Three groups of lice $(\mathrm{n}=3$ each) were placed into a $1.5 \mathrm{~mL}$ microfuge tube containing $1 \mathrm{~mL}$ of tap water and kept immersed for $10 \mathrm{~min}, 3 \mathrm{~h}$ or $24 \mathrm{~h}$. Control groups were placed into $1.5 \mathrm{~mL}$ tubes without water. Upon completion, lice were frozen at $-20^{\circ} \mathrm{C}$ to preserve the status of the spiracles (SEM1). A similar series of experiments (SEM2) was performed except that $-20^{\circ} \mathrm{C}$ refrigeration was replaced by liquid nitrogen immersion to avoid rapid movement of the spiracles. After a rapid thaw, specimens were mounted on aluminium stubs on double-sided conductive carbon tabs and positioned on the stubs using a stereoscopic microscope. Samples were analyzed using a FEI Quanta FEG 250 environmental scanning electron microscope operating in LowVac mode, enabling the observation of resin coated samples without metallization and ESEM mode, which is normally used for the observation of wet samples (Technology University of Compiègne, France). The chamber pressure was 3 Torr, the Horizontal Field Width was $63.5 \mu \mathrm{m}$, and the working distance was $10 \mathrm{~mm}$ with a tilt of $-1^{\circ}$. The images were recorded at $1536 \times 1103$ pixel magnification.

\section{Penetration of water, dimeticone/cyclomethicone and ethanol into the respiratory system}

Penetration or absence of penetration of liquids through the spiracles into the respiratory system was studied using a water-based stain, an absolute ethanol- 
based stain, and dimeticone/cyclomethicone-based stain (Pouxit ${ }^{\circledR}$, Cooper, France). The latter contains $4 \% \mathrm{w} / \mathrm{w}$ dimeticone in a volatile silicone base (cyclomethicone 5).

The stain $(0.1 \%)$ in water and absolute ethanol was brilliant blue FCF (E133) (Meilleurduchef, France). The stain (1\%) in dimeticone/cyclomethicone was a red lipophilic colorant (FluoTecknic, France).

Nine groups of lice $(\mathrm{n}=3$ each) were placed into a $1.5 \mathrm{~mL}$ microfuge tube containing either (i) $1 \mathrm{~mL}$ of blue tap water or $1 \mathrm{~mL}$ of blue absolute ethanol, or (ii) $1 \mathrm{~mL}$ of red dimeticone/cyclomethicone. Lice were kept immersed for $10 \mathrm{~min}, 30 \mathrm{~min}$ or $12 \mathrm{~h}$. Controls consisted of 9 groups of lice $(\mathrm{n}=3$ each), which were processed identically, except for the absence of dye. After immersion, lice were dried gently on a filter paper to absorb excess of fluid and then abundantly rinsed with tap water before examination under a binocular magnifier.

\section{Statistical analysis}

The survival of lice after immersion or anoxia bioassays was expressed as the percentage of living specimens. For immersion and anoxia bioassays, the Fisher's exact test was used to compare the survival rate between groups, looking for a relationship with time of immersion or exposure by the Cochran-Mantel-Haenszel tests. For anoxia bioassay, the 3-way ANOVA model with interaction was used to check whether the treatment (anoxia or control) remains independent of the time of exposure. The analyses were carried out at the two-tailed $p<0.05$ level using JMP version 10.0.0 (SAS Institute, Cary, NC, USA).

\section{Results}

\section{Anoxia bioassay}

A total of 1,787 head lice were used for this study. In all, 900 lice were held under anoxic conditions and 887 lice were used as untreated controls. Those placed in the anaerobic pouches remained mobile for at least $5 \mathrm{~min}$. After $10 \mathrm{~min}$, intestinal peristalsis and legs/antennae movement showed decreased activity. After 30-40 min, all lice appeared completely immobile. After extraction from the anaerobic pouches at $\mathrm{H} 1, \mathrm{H} 3, \mathrm{H} 6$ or $\mathrm{H} 8,100 \%$ $(360 / 360)$ of lice were alive compared with $87.1 \%(305 /$ $350)$ in the matched control groups $(p<0.0001)$. After H10, death was observed in the anoxic group (Figure 1). At H14, the survival rate in the anoxic group was lower $12.2 \%(11 / 90)$ than in the control group $48.9 \%$ (44/90). All treated lice were dead after H16 vs survival rates of $18.9 \%(17 / 90)$ at $\mathrm{H} 16,11.1 \%(10 / 90)$ at $\mathrm{H} 18$, and $10 \%$ (9/ 90) at $\mathrm{H} 24$ in the untreated control groups.

\section{Survival of lice following immersion in water}

A total of 503 head lice were used, of which 243 were immersed in water and 260 were used as untreated controls. Following immersion in water, antennae and leg movement of all lice ceased within less than $1 \mathrm{~min}$, while intestinal peristalsis persisted for up to $10 \mathrm{~min}$, then lice

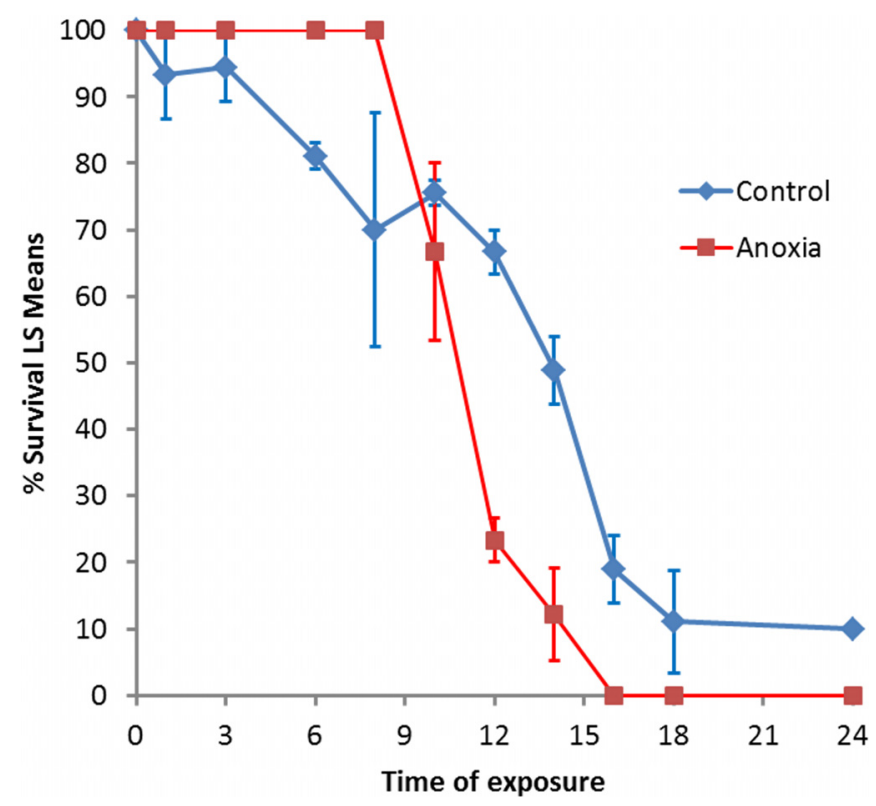

Figure 1. Survival of head lice after anoxia exposure compared with control lice maintained at ambient temperature.

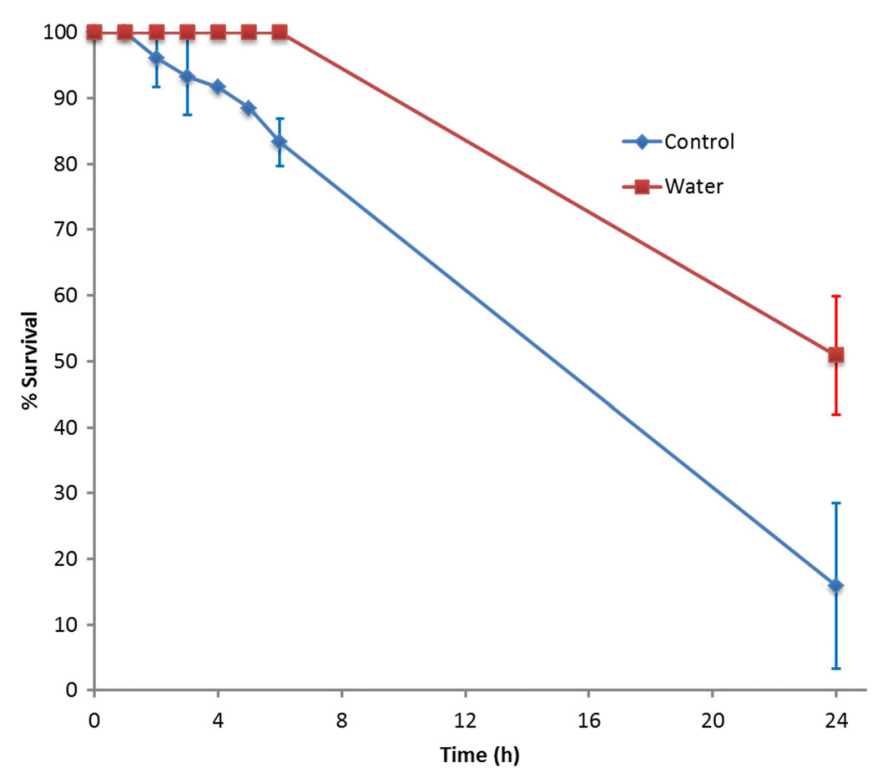

Figure 2. Survival of head lice after immersion in water for $1 \mathrm{~h}$ to $6 \mathrm{~h}$, and $24 \mathrm{~h}$ compared with control lice maintained at ambient temperature.

appeared completely immobile. However, none of the 188 lice immersed between $\mathrm{H} 1$ and $\mathrm{H} 6$ were dead, despite their apparent immobility. After H24, 50.9\% (28/55) of water-immersed lice were alive. Mortality was higher in the control group compared with the test group (Figure 2). The dynamics of recovery were recorded; gut peristalsis and movements of antennae resumed within $5 \mathrm{~min}$ following 1-3 h immersion, and after $10 \mathrm{~min}$ following 4$6 \mathrm{~h}$ immersion. For those immersed for $24 \mathrm{~h}, 23.6 \%(13 / 55)$ showed slight movement of legs, antennae or gut 
peristalsis when released from the immersion conditions; 20 min later, the whole body convulsed [43.6\% (24/55)] and after 1 hour, $50.9 \%(28 / 55)$ of these lice were alive and fully active.

\section{Effect of water immersion on lice spiracles}

A total of 36 lice were aliquoted into 6 study groups $(\mathrm{n}=3$ each $)$ and 6 untreated control groups $(\mathrm{n}=3$ each $)$. Irrespective of the specific experiment (water-immersed or non-immersed) and the freezing method $\left(-20^{\circ} \mathrm{C}\right.$ or $\left.-196{ }^{\circ} \mathrm{C}\right)$, the diameter of the thoracic and abdominal spiracles measured approximately $20 \mu \mathrm{m}$ (Figure 3a) and $\sim 5 \mu \mathrm{m}$ (Figure 3b), respectively. We also noted that abdominal and thoracic spiracles from water-immersed lice contained a secreted material (Figure 3c).

\section{Penetration of water, dimeticone/cyclomethicone or ethanol into the respiratory system}

A total of 54 head lice were used for this study. All lice immersed in water containing stain (Figure 4i, j, k) showed a total lack of coloration of the tracheal system regardless of the duration of contact $(10 \mathrm{~min}, 30 \mathrm{~min}$, or $12 \mathrm{~h}$ ). On the other hand, colored ethanol stained the lice spiracles within $10 \mathrm{~min}$ of contact (Figure 4a) and the entire tracheal system was colored after either $30 \mathrm{~min}$ or $12 \mathrm{~h}$ (Figure 4b, c). Likewise, colored-dimeticone/cyclomethicone stained the lice spiracles within $10 \mathrm{~min}$ of contact (Figure 4e). After $30 \mathrm{~min}$ and $12 \mathrm{~h}$, the entire tracheal system of the head lice was red-colored, indicating that the stained-dimeticone/cyclomethicone had filled the tracheal system (Figure 4f, g). Lice immersed in colored or non-colored dimeticone/cyclomethicone or $100 \%$ ethanol were all dead following immersion for $30 \mathrm{~min}$.

\section{Discussion}

\section{General observations}

Head lice cause skin irritation, superinfection from scratching, and might also transmit severe infectious diseases under endemic or epidemic conditions [2]. For centuries, humans have attempted to combat head lice infestation. Remnants of these practices can be observed in non-human primates in which de-lousing has turned into a social activity. In response to increasing resistance encountered with neurotoxic insecticides, alternative treatments relying on physical properties, rather than chemicals, have been developed and evaluated either in vitro, clinically or both. Most of these treatments are based on oils, alcohol or plant extracts $[1,7,10,21,34$, $35,43,44,48,57]$. The claimed mechanisms of action of these compounds rely either (i) on blocking the penetration of the compounds at the surface of the nits and lice [35,44], or (ii) on penetration of the trachea $[1,48]$. Since these compounds block air uptake by lice, it was extrapolated that death occurred by asphyxiation/ suffocation. However, the precise mechanisms leading to
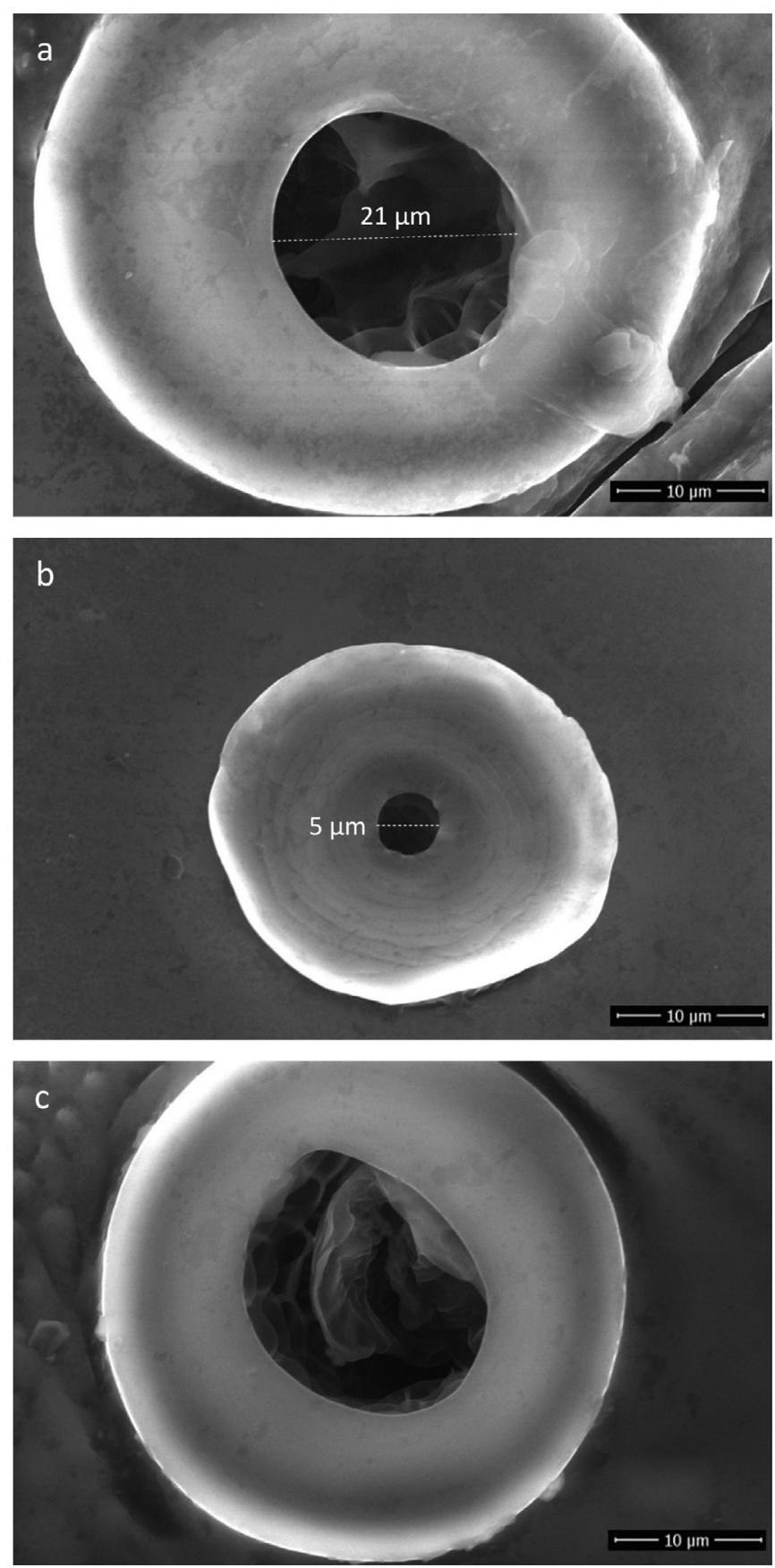

Figure 3. Representative scanning electron micrographs showing morphology of head lice spiracles after $24 \mathrm{~h}$ water immersion: a) Thoracic spiracle, b) Abdominal spiracle, c) Thoracic spiracle showing secreted material.

death in these conditions has been questioned [10,11]. For these reasons, we decided to investigate whether or not anoxia was effective against lice and for how long lice could endure oxygen deprivation. We also evaluated lice survival after immersion in water, to study whether or not their respiratory system was protected by closing the spiracles, and how effective the spiracles were at preventing entry of liquid into the respiratory system. 


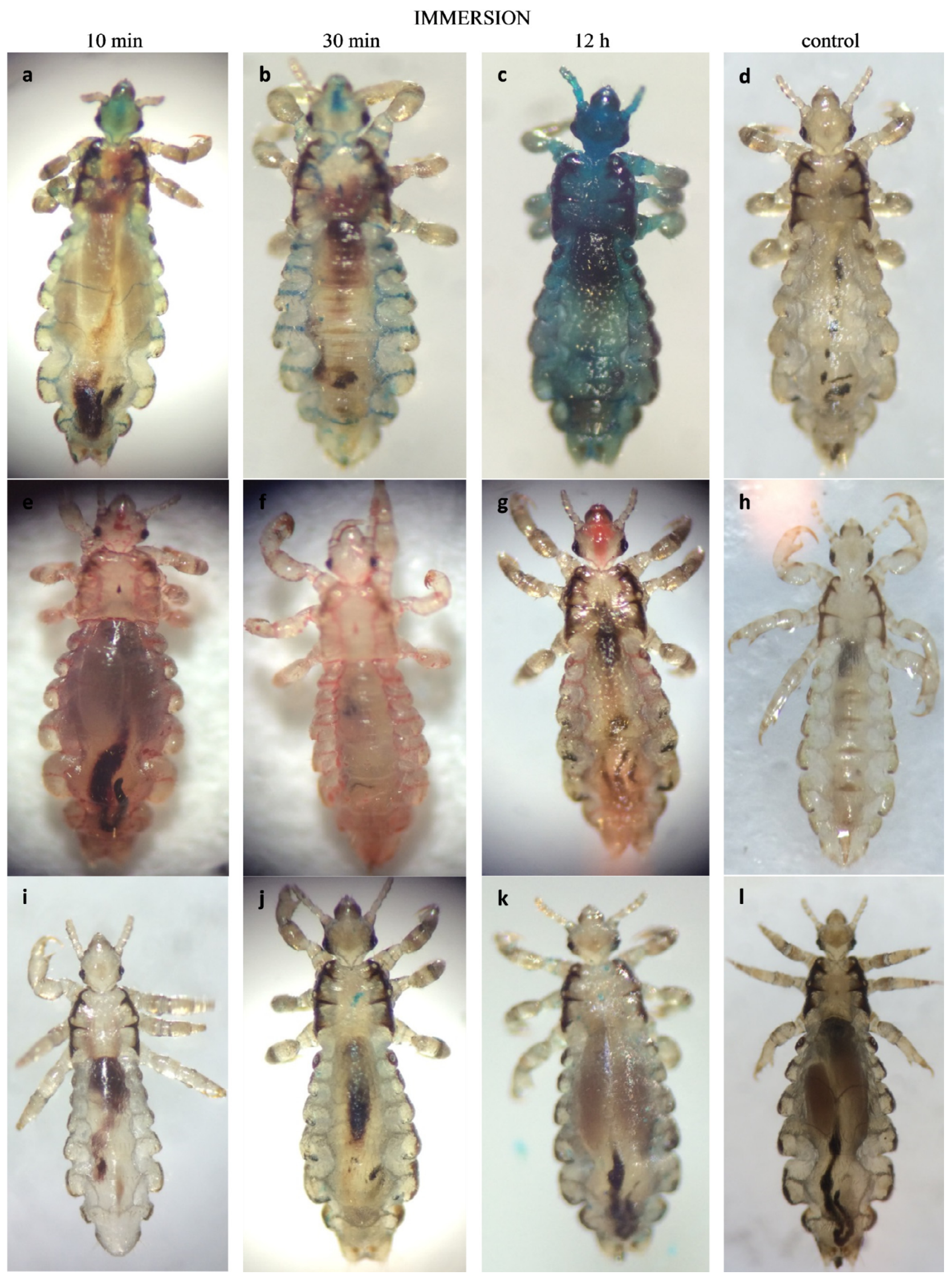

Figure 4. Photographs of head lice immersed in ethanol (first row), in dimeticone/cyclomethicone (second row) or in water (third row). Dark-blue stained ethanol entered across spiracles and filled the respiratory system (a, b, c), control (d). Red-stained dimeticone/ cyclomethicone entered across spiracles and filled the respiratory system $(\mathrm{e}, \mathrm{f}, \mathrm{g})$, control $(\mathrm{h})$. Dark blue stained water did not penetrate the respiratory system (i, j, k), control (l). 


\section{Anoxia bioassay}

Data to quantify how long head lice can survive under anoxic conditions are lacking. This study showed that oxygen deprivation caused higher mortality rates of all groups subjected to this condition for $>8 \mathrm{~h}$, when compared with untreated controls (survival $12.2 \%$ vs $48.9 \%$, $p<0.0001$ ). The fact that after $14 \mathrm{~h}$ of anoxia, only $12.2 \%$ of lice were alive compared with $48.9 \%$ of controls demonstrates that either long-term oxygen deprivation or carbon dioxide increases, ranging from 8 to $16 \%$ (after $24 \mathrm{~h}$ /or both) kill lice. The AnaeroGen ${ }^{\mathrm{TM}}$ sachet reduces oxygen to $<0.1 \%$ within $2.5 \mathrm{~h}$, while generating $8-16 \%$ carbon dioxide, suggesting that lice are adapted to total oxygen deprivation for 10-12 h. Death of lice by asphyxiation was claimed for several physically active treatments $[1,35,44,48]$. Depending on the concentrations used and the exposure period, carbon dioxide may have a variety of impacts on insects including bait, anesthesia, and pest control. Additionally, the carbon dioxide effect may vary from being innocuous to having a severe impact on lice survival depending on concentration, temperature, insect species, or other factors $[29,45,46]$. In contrast to reported studies that used either very high carbon dioxide concentrations for a short period of time or low concentrations for longer exposure periods, we maintained lice for $<24 \mathrm{~h}$ in the AnaeroGen ${ }^{\mathrm{TM}}$ pouch where carbon dioxide levels never exceeded $16 \%$. After $16 \mathrm{~h}$ of anoxia, the death rate was very high. A limitation of our study was that controls were maintained in an ambient atmosphere rather than in anaerobic pouches, i.e. without use of the AnaeroGen ${ }^{\mathrm{TM}}$ sachet. Thus, the high mortality rate in the untreated controls during the first few hours could be due to dehydration.

\section{Lice survival after water immersion}

When immersed in water, we observed a survival rate of $100 \%$ after $6 \mathrm{~h}$, and $50 \%$ after $24 \mathrm{~h}$; during these experiments louse mobility ceased totally. The latter observation had also been reported in previous studies with head lice [15] and amphibious lice (Antarctophthirus microchir) [32]. Our results are of the same magnitude as described for body lice by Mumcuoglu et al. [38] (100\% mortality rate after $19 \mathrm{~h}$ in $24^{\circ} \mathrm{C}$ water). At $-1{ }^{\circ} \mathrm{C}$, body lice can survive for up to $67 \mathrm{~h} \mathrm{[4].} \mathrm{For} \mathrm{head} \mathrm{lice,} \mathrm{there} \mathrm{was}$ only one previous study that reported a much higher mortality after water immersion ( $87 \%$ and a $100 \%$ death rate after $12 \mathrm{~h}$ and $16 \mathrm{~h}$, respectively) [53]. Takano-Lee et al. [53] observed that 13\% $(\mathrm{n}=8)$ of head lice recovered following water immersion for $12 \mathrm{~h}$, but that $100 \%(\mathrm{n}=20)$ of lice were killed after $16 \mathrm{~h}$ of immersion. The fact that mortality was higher in untreated controls than in immersed lice may reflect the total immobility induced by water immersion; since water is not rapidly toxic for lice, the absence of movement reduces metabolic activity, which could otherwise be deleterious if combined with starving; in addition, control lice may also have suffered from dehydration. Whether head lice, immersed in water, die from anoxia or from drowning due to penetration of water into their respiratory system was never investigated.

\section{Effect of water immersion on louse spiracles}

From the outset of this study, it was common knowledge that head lice immersed in water protect their respiratory system from water penetration either by closing their spiracles $[3,12,31,33,34]$, or by closing hypothetical anatomic structures located below the spiracles $[14,20,42,55]$. However, these two putative mechanisms have not been further documented and remain hypothetical. Meinking et al. [34] observed that lice immersed in mayonnaise sauce presented clogged spiracles but no evidence of closed spiracles. Buxton [14], Ferris [20], Nuttall et al. [42], and Webb [55] described an occlusor muscle in Anoplura species, including Pediculus. It is generally accepted that the inner occlusor muscle in Anoplura species works to close the spiracles [14,20,42,55], in order to restrict water loss [14]. However, to date, the exact function of this muscle remains obscure. In our study, we observed (i) that the trachea was not closed and presented a honeycomb internal structure, and (ii) the presence of a secreted material in spiracles as well as glands at the base of the spiracles that might be responsible for the production of this substance. However, detailed studies are needed to characterize both glands and material in more detail.

Our results showed that blocking water penetration into the respiratory system of head lice is not mediated by physically closing the spiracles or decreasing their diameter. Freezing at $-20^{\circ} \mathrm{C}$ is a relatively slow process and might result in erroneous conclusions concerning the condition of spiracles at any precise moment. For this reason, and to avoid any bias due to instant contraction of the spiracles, if any, a second experiment was performed using liquid nitrogen $\left(-196^{\circ} \mathrm{C}\right)$ that results in instant freezing of the physical state of spiracles during immersion. Interestingly, modification of the diameter of spiracles through slow or instant closing was not observed in our study. There was no difference in the size of spiracle diameter when lice were in the air or in water; prevention of water penetration probably relies on an alternative mechanism. This contradicts previous reports, which on examination brought little insight on the mechanism itself $[3,12,31,33]$.

\section{Penetration of water, dimeticone/cyclomethicone and ethanol into the respiratory system}

As far as we are aware, water ingress through spiracles during the immersion process has never been demonstrated. In our study, although all water-immersed head lice showed open spiracles, colored water did not penetrate into the respiratory system (Figure 4i-k). However, the precise mechanism of preventing water penetration has not been elucidated. Nevertheless, we noted the presence of secretions of an unidentified substance in the spiracles of 
water-immersed head lice (Figure 3c); a similar finding was described by Burgess [10]. Albeit refuted by Ferris [20], Webb [55] described a gland associated with the atrium of lice (atrial glands) that discharges a waxy material in the atrium. Webb suggested the role of dust blockage, but the physical and chemical nature of this substance remains unknown.

In contrast with what was observed following water immersion, the respiratory system of lice immersed in ethanol was flooded within half an hour (Figure 4b). This is in agreement with results reported by Meinking et al. with benzyl alcohol [34]; however, the latter suggested that alcohol ingress may have stunned the spiracle in some ways. However, in light of our results, alternative possibilities need to be investigated. Because of its toxicity, flooding of the respiratory system with alcohol results in the death of head lice $[37,47,50]$. In addition, the dark blue staining observed not only in the respiratory system but in the whole body is due to ethanol ingress through the cuticle of the insect (Figure 4c) as previously described [56].

Dimeticone/cyclomethicone appears to have entered through the spiracles to flood the respiratory system in a similar manner, which results in head lice death within 30 min. Death can be explained by (i) the impossibility for head lice to expel dimeticone/cyclomethicone out of the respiratory system, whereby the insect dies by suffocation as previously reported [48], or (ii) the inhibition of water excretion leading to osmotic stress due to the clogging of spiracles, as described [10]. We used the same formulation (4\% dimeticone/cyclomethicone 5, Pouxit ${ }^{\circledR}$ ) as Burgess [10], and our results appear to confirm the "suffocation hypothesis" proposed by Richling and Böckeler [48] (Figure 4f).

In this study, experiments were performed on head lice collected from several patients from various ethnic communities and the therapeutic history of each patient was not known.

To conclude, a better understanding of the environmental adaptation of lice to the human host may allow us to find improved methods to control head lice.

In this study, we showed that head lice were capable of physiological or behavioral adaptations for surviving anoxia and immersion in water. They can endure anoxia for several hours and are resistant to immersion in water without obvious deleterious effects on movements and survival. Such findings must be taken into account to provide innovative and effective countermeasures against head lice infestation. It appears that efficacy is related to physical entry into the respiratory system that can be easily monitored using dyes.

Acknowledgments. The authors thank Professor Ernest A. Gould for English revision and clever comments. Kerdalidec Candy was supported by the fund of the Ministry of Higher Education and Research of France, managed by the Association Nationale de la Recherche et de la Technologie (ANRT). The funders had no role in study design, data collection and analysis, decision to publish, or preparation of the manuscript.

\section{Conflict of interest}

The authors declare that they have no competing interests.

\section{References}

1. Al-Quraishy S, Abdel-Ghaffar F, Mehlhorn H. 2015. Head louse control by suffocation due to blocking their oxygen uptake. Parasitology Research. 114, 3105-3110.

2. Amanzougaghene N, Akiana J, Mongo Ndombe G, Davoust B, Nsana NS, Parra HJ, Fenollar F, Raoult D, Mediannikov O. 2016. Head lice of pygmies reveal the presence of relapsing fever borreliae in the Republic of Congo. PLOS Neglected Tropical Diseases, 10, e0005142.

3. Bacot A, Lloyd L. 1919. Experiments on the destruction of lice and nits: II. Experiments concerning the destruction of active lice (Pediculus humanus) by solutions of cresol soap emulsion and lysol, and of lice and nits with kerosene, with a view to the use of these remedies for the treatment of verminous heads. British Medical Journal, 2(3074), 703-705.

4. Bacot A, Talbot G. 1919. Experiments on the destruction of lice and nits: I. the survival period of lice and nits (Pediculus humanus) when submerged in tap water and water containing 1 per cent of salt at various temperatures. British Medical Journal, 2(3074), 703-705.

5. Bonilla DL, Kabeya H, Henn J, Kramer VL, Kosoy MY. 2009. Bartonella quintana in body lice and head lice from homeless persons, San Francisco, California, USA. Emerging Infectious Diseases, 15, 912-925.

6. Bouvresse S, Socolovshi C, Berdjane Z, Durand R, Izri A, Raoult D, Chosidow O, Brouqui P. 2011. No evidence of Bartonella quintana but detection of Acinetobacter baumannii in head lice from elementary school children in Paris. Comparative Immunology, Microbiology \& Infectious Diseases, 34, 475-477.

7. Burgess IF, Brunton ER, Burgess NA. 2010. Clinical trial showing superiority of a coconut and anise spray over permethrin $0.43 \%$ lotion for head louse infestation. European Journal of Pediatrics, 169, 55-62.

8. Burgess IF, Silverston P. 2015. Head lice. BMJ Clinical Evidence, 01, 1703.

9. Burgess IF. 2009. Current treatments for pediculosis capitis. Current Opinion in Infectious Diseases, 22, 131-136.

10. Burgess IF. 2009. The mode of action of dimeticone $4 \%$ lotion against head lice, Pediculus capitis. BMC Pharmacology, 9, 3 .

11. Burkhart CG, Burkhart CN. 2006. Asphyxiation of lice with topical agents, not a reality...yet. Journal of the American Academy of Dermatology, 54, 721-722.

12. Burkhart CN, Burkhart CG, Gunning WT. 2000. Scanning electron microscopy of adult head lice (Pediculus humanus capitis) with focus on clinical implications. Journal of Cutaneous Medicine and Surgery, 4, 181-185.

13. Busvine, JR. 1944. Destruction of lice in clothing by hot and cold air. Bulletin of Entomological Research, 35, 115-125.

14. Buxton PA. 1947. The Louse. An account of the lice which infest man, their medical importance and control. London: Edward Arnold \& Co.

15. Canyon D, Speare R. 2007. Do head lice spread in swimming pools? International Journal of Dermatology, 46, 1211-1213.

16. Chosidow O, Giraudeau B, Cottrell J, Izri A, Hofmann R, Mann SG, Burgess I. 2010. Oral ivermectin versus malathion lotion for difficult-to-treat head lice. New England Journal of Medicine, 362, 896-905. 
17. Chosidow O. 2000. Scabies and pediculosis. Lancet, 355, 819-826.

18. Durand R, Bouvresse S, Berdjane Z, Izri A, Chosidow O, Clark JM. 2012. Insecticide resistance in head lice: clinical, parasitological and genetic aspects. Clinical Microbiology and Infection, 18, 338-344.

19. Falagas ME, Matthaoui DK, Rafailidis PI, Panos G, Pappas G. 2008. Worldwide prevalence of head lice. Emerging Infectious Diseases, 14, 1493-1494.

20. Ferris GF. 1951. The sucking lice. Pacific Coast Entomological Society, 320 pp.

21. Gallardo A, Mougabure-Cueto G, Vassena C, Picollo MI, Toloza AC. 2012. Comparative efficacy of new commercial pediculicides against adults and eggs of Pediculus humanus capitis (head lice). Parasitology Research, 110, 1601-1606.

22. Goates BM, Atkin JS, Wilding KG, Birch KG, Cottam MR, Bush SE, Clayton DH. 2006. An effective nonchemical treatment for head lice: a lot of hot air. Pediatrics, 118, 19621970.

23. Goldberger J, Anderson JF. 1912. The transmission of Typhus fever, with especial reference to transmission by the head louse (Pediculus capitis). Public Health Reports (18961970), 27, 297-307.

24. Gordon SC. 2007. Shared vulnerability: a theory of caring for children with persistent head lice. Journal of School Nursing, 23, 283-292.

25. Gratz NG. 1997. Human Lice. Their prevalence, control and resistance to insecticides. WHO/CTD/WHOPES/97. 8. Geneva: WHO.

26. Gur I, Schneeweiss R. 2009. Head lice treatments and school policies in the US in an era of emerging resistance: a costeffectiveness analysis. Pharmacoeconomics, 27, 725-34.

27. Hansen RC, O'Haver J. 2004. Economic considerations associated with Pediculus humanus capitis infestation. Clinical Pediatrics, 43, 523-527.

28. Heukelbach J, Oliveira FA, Richter J, Häussinger D. 2010. Dimeticone-based pediculicides: A physical approach to eradicate head lice. Open Dermatology Journal, 4, 77-81.

29. Husain M, Rasool KG, Tufail M, Alhamdan AM, Mehmood K, Aldawood AS. 2015. Comparative efficacy of CO2 and ozone gases against Ephestia cautella (Lepidoptera: Pyralidae) larvae under different temperature regimes. Journal of Insect Science, 15, pii: 126.

30. Izri A, Chosidow O. 2006. Efficacy of machine laundering to eradicate head lice: recommendations to decontaminate washable clothes, linens, and fomites. Clinical Infectious Diseases, 42, e9-e10.

31. Landois L. 1865. Untersuchungen über die auf dem Menschen schmarotzenden Pediculinen. Zeitschrift für Wissenschaftliche Zoologie, 15, 494-503.

32. Leonardi MS, Aznar FJ, Crespo EA, Lazzari CR. 2014. Uncovering deep mysteries: the underwater life of an amphibious louse. Journal of Insect Physiology, 71, 164-169.

33. Maunder JW. 1983. "The Appreciation of Lice". Proceedings of the Royal Institute of Chemistry of Great Britain, 55, 131.

34. Meinking TL, Villar ME, Vicaria M, Eyerdam DH, Paquet D, Mertz-Rivera K, Rivera HF, Hiriart J, Reyna S. 2010. The clinical trials supporting benzyl alcohol lotion $5 \%$ (Ulesfia): a safe and effective topical treatment for head lice (pediculosis humanus capitis). Pediatric Dermatology, 27, 19-24.

35. Militão de Sousa F, Vasconcelos AW, de Nadon J, Duhot PY. 2010. Treatment of human head lice infestations in a single application with a new galenic lotion. International Journal of Cosmetic Science, 32, 369-375.
36. Moore W. 1918. The effect of laundering upon Lice (Pediculus corporis) and their eggs. Journal of Parasitology, 5, 61-68.

37. Mougabure Cueto G, Inés Picollo M. 2010. Response of Pediculus humanus humanus (Pediculidae: Phthiraptera) to water or $70 \%$ ethanol immersion and determination of optimal times for measuring toxic effects. Parasitology Research, 106, 1503-1506.

38. Mumcuoglu KY, Friger M, Cohen R. 2006. Use of temperature and water immersion to control the human body louse (Anoplura: Pediculidae). Journal of Medical Entomology, 43, 723-725.

39. Mumcuoglu KY, Klaus S, Kafka D, Teiler M, Miller J. 1991. Clinical observations related to head lice infestation. Journal of the American Academy of Dermatology, 25, $248-51$.

40. Mumcuoglu KY, Meinking TA, Burkhart CN, Burkhart CG. 2006. Head louse infestations: the "no nit" policy and its consequences. International Journal of Dermatology, 45, 891-896.

41. Murray ES, Torrey SB. 1975. Virulence of Rickettsia prowazekii for head lice. Annals of the New York Academy of Sciences, 266, 25-34.

42. Nuttall GHF, Keilin D. 1930. Iconographic Studies of Pediculus humanus. Molteno Institute for Research in Parasitology, 22 (1), pp 1-10.

43. Oliveira FA, Speare R, Heukelbach J. 2007. High in vitro efficacy of Nyda L, a pediculicide containing dimeticone. Journal of the European Academy of Dermatology and Venereology, 2, 1325-1329.

44. Pearlman DL. 2004. A simple treatment for head lice: dryon, suffocation-based pediculicide. Pediatrics, 114, e275e279.

45. Perron JM, Huot L, Corrivault GW, Chawla SS. 1972. Effects of carbon dioxide anaesthesia on Drosophila melanogaster. Journal of Insect Physiology, 18, 1869-74.

46. Reeves WC. 1951. Field studies on carbon dioxide as a possible host simulant to mosquitoes. Proceedings of the Society for Experimental Biology and Medicine, 77, 64-66.

47. Reynolds JEF, Prasad AB. 1982. Alcohol. In: Martindale: The extra pharmacopeia, 28th ed. London: The pharmaceutical press. p. 35-41.

48. Richling I, Böckeler W. 2008. Lethal effects of treatment with a special dimeticone formula on head lice and house crickets (Orthoptera, Ensifera: Acheta domestica and Anoplura, Phthiraptera: Pediculus humanus). Arzneimittelforschung, 58, 248-254.

49. Robinson D, Leo N, Prociv P, Barker SC. 2003. Potential role of head lice, Pediculus humanus capitis, as vectors of Rickettsia prowazekii. Parasitology Research, 90, 209-211.

50. Rutkauskis JR, Jacomini D, Temponi LG, Sarragiotto MH, da Silva EA, Jorge TC. 2015. Pediculicidal treatment using ethanol and Melia azedarach L. Parasitology Research, 114, 2085-2091.

51. Speare R, Cahill C, Thomas G. 2003. Head lice on pillows, and strategies to make a small risk even less. International Journal of Dermatology, 42, 626-629.

52. Speare R. 2000. Hot water kills head lice experimentally placed on brushes. International Journal of Dermatology, 39, 952-954.

53. Takano-Lee M, Edman JD, Mullens BA, Clark JM. 2004. Home remedies to control head lice: assessment of home remedies to control the human head louse, Pediculus humanus capitis (Anoplura: Pediculidae). Journal of Pediatric Nursing, 19, 393-398. 
54. Veracx A, Raoult D. 2012. Biology and genetics of human head and body lice. Trends in Parasitology, 28, 563-571.

55. Webb JE. 1946. Spiracle structure as a guide to the phylogenetic relationships of the Anoplura (biting and sucking lice), with notes on the affinities of the mammalian hosts. Proceedings of the Zoological Society, 116, 49-119.
56. Wigglesworth VB. 1948. The insect cuticle. Biological Reviews of the Cambridge Philosophical Society, 23, 408-51.

57. Wolf L, Eertmans F, Wolf D, Rossel B, Adriaens E. 2016. Efficacy and safety of a mineral oil-based head lice shampoo: A randomized, controlled, investigator-blinded, comparative study. PLoS One, 11, e0156853.

Cite this article as: Candy K, Brun S, Nicolas P, Durand R, Charrel RN, Izri A. 2018. Do drowning and anoxia kill head lice?

Parasite 25, 8

\section{O PARASTE}

Reviews, articles and short notes may be submitted. Fields include, but are not limited to: general, medical and veterinary parasitology; morphology, including ultrastructure; parasite systematics, including entomology, acarology, helminthology and protistology, and molecular analyses; molecular biology and biochemistry; immunology of parasitic diseases; host-parasite relationships; ecology and life history of parasites; epidemiology; therapeutics; new diagnostic tools.

All papers in Parasite are published in English. Manuscripts should have a broad interest and must not have been published or submitted elsewhere. No limit is imposed on the length of manuscripts.

Parasite (open-access) continues Parasite (print and online editions, 1994-2012) and Annales de Parasitologie Humaine et Comparée (1923-1993) and is the official journal of the Société Française de Parasitologie. 